\title{
The Innovative Application of Surface Texture in Fashion and Textile Design
}

\author{
Lin Gong and Jooyoung Shin ${ }^{\dagger}$ \\ Institute of Textiles and Clothing, The Hong Kong Polytechnic University, Hong Kong
}

\begin{abstract}
This study focuses on 'texture' as one of the most important fashion and textile design elements; in addition, it proposes various applications of it. Surface texture is indispensable in fashion and textile design that also factors heavily into innovative creations. Along with technological advances in the fashion industry, surface texture has derived many new and attractive features that provide more opportunities for designers to show various design concepts. Rather than the surface quality of fabrics, surface texture in fashion design creates its identity through a manipulation of materials- an application that tends to be primarily for visual effects without being restricted to decorative purposes. The status and significance of surface texture in various creative fields is explored and the evolution of surface texture is traced by analyzing a number of fashion design cases with representative surface textures. The latest feature of surface texture in fashion and textile design is identified to establish a new classification of surface texture with five groups and technical suggestions. This study provides a theoretical basis for this field of study and a new framework that can be employed in the development of surface textures that use innovative techniques as well as the future application of newly-developed textures.
\end{abstract}

Key words: fashion, textile, surface, texture, classification

\section{Introduction}

Textures appear on the surface of everything. Markov stated: "From the beginning of time, nature has been processing all materials and creating textures. Organic life on earth is a chaos of constantly changing texture"(as cited in Hilliard \& Cliff, 2002). Roughness, smoothness, hardness, or softness of texture can be felt by touch and by visual suggestion through intercepting light rays, producing light and shadow. Besides sight and touch, texture also integrates the audience's sense of hearing(Davis, 1996; Pipes, 2003). People can distinguish clay and stone not only by the tactile sense, but also by their visual representations and even the sound made by a knocking knuckle. Also, texture characterizes the surface of an object and often exists with a functional purpose in the world of nature and people's life. Hedgehogs have spines all over their body for protective purposes; sharks' smooth skin allows rapid movement through water; tires are made rough to increase friction so as to enhance safety; and Chinese medicine sees its massage slippers apply dozens of designed columns underfoot for health-related functions. Textures are essential for people to be able to feel the world. The materials around us can be distinguished by feeling, helping us to recognize familiar substances when we next see or touch them and identify those unusual or unfamiliar(Preble et al., 2002; Gatto et al., 2000).

†Corresponding author; Jooyoung Shin

Tel. +852-2766-7871, Fax. +852-2773-1432

E-mail: tcshinjy@polyu.edu.hk
In visual art and design, texture is one of the principal design elements. The way that a surface looks cannot be divorced from texture(Hilliard \& Cliff, 2002). Two sensory processes of visual and tactile senses can be motivated in both two- and three- dimensional fields so texture can be unique among art and design elements(Ocvirk et al., 2002). The effect of surface texture has been paid careful attention in works of art(Gatto et al., 2000). Texture creation is a developable and interesting point for various creative fields, such as fine arts, architecture, interior, fashion and textiles. Innovation is limited for simple designs of daily objects, based on product requirements or functions. For example, dinnerware should not be too rough since using or cleaning it would then be problematic. On the other hand, texture can be novel and creative in artwork and conceptual designs. In the fashion industry, texture cannot be randomly applied or created due to the functional requirements of garments. Besides this case, appearance or aesthetic quality is one of the most important aspects of fashion design(Fan et al., 1999), and the surface texture of fabric is one of the major characteristics that determines the appearance of a garment(Sirikasemlert \& Tao, 2000). As a unique element in fashion and textile design, surface texture can be used to express a designer's aesthetic perspective and design concept.

The application of surface texture should thrive and be in control so as to be effective, appealing, and corresponding to design concepts. A clear perception on applying and programming surface texture is necessary for assisting or coordinating the process of fashion design. This study aims to establish theoretical and sys- 
tematic classifications of innovative surface textures with related technical suggestions for fashion design. In order to achieve this aim, the following principal ideas have been explored and developed. First, the status and significance of surface texture is recognized through literary study with references to art and other fields of design. Second, the evolution of texture creations and applications in fashion design is traced by analyzing several cases, in which applied techniques and the appearances of surface textures are discussed. Third, a new definition of texture in fashion design has been built, based on the manner in which that texture evolved. Finally, innovative methods and techniques that are capable of creating texture in fashion design are explored and suggested.

\section{Texture as an Innovative Element in Creative Fields}

\subsection{Definition of texture}

Texture denotes the quality of surfaces and the characteristic physical structure of material. People feel their surroundings by means of looking and touching surfaces. The materials around can be distinguished by feeling diverse textures, which helps us recognize familiar substances when we again see or touch the surface texture and identify unusual or unfamiliar textures(Preble et al., 2002; Gatto et al., 2000). The way to feel a texture depends on the degree to which a surface is broken up by its composition(Ocvirk et al., 2002) and how it reflects light(Buckner, 1995). Fig. 1 shows a visualized comparison among three different degrees of a broken surface by three different fabrics. The left one is satin that stands for a smooth substance; in the middle is a piece of pleated fabric; and it is a bulky knit on the right. As seen in the figure, less shadow is produced on the smooth satin, but there are shadows and highlights on the left and the right side of undulations on the pleated fabric, and shadows among the stitches on the bulky knit. Glossy surfaces can evenly reflect the light and give a less broken look whereas rough surfaces produce light and shadows because light rays are intercepted by the unevenness(Ocvirk et al., 2002). The

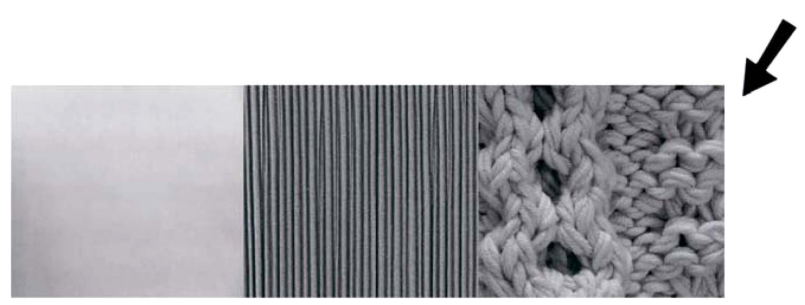

Fig. 1. Three different broken surfaces on satin, pleated fabric and bulky knit (the arrow in this figure indicates the direction of light source) ${ }^{1}$ ${ }^{1}$ :This and any subsequent uncredited tables and figures are the work of the author. ability to see texture is related to the interaction with light that the extent of a material reflects or absorbs(Ellinwood, 2011). Thus, texture can be felt and texture appearance is related to light and shadow patterns.

In visual art and design, texture is the surface character of created work(Buckner, 1995). It makes a surface or substance feel or look different from its color or shape whether the surface is rough, smooth, rugged, or silky(Beaney, 1978). It is the surface characteristic of a material or a result of how the material has been manipulated by an artist or a designer in two-dimensional and threedimensional fields. Davis(1996) defined the term 'texture' as a tangible structure surface or a manipulated three-dimensional substance, and the visual qualities of surface and substance. The feature of texture evolves with changes and trends of art and design from the actual texture of materials to creatively invented texture by development of creative approaches. Textures for routine designs, like daily supplies, are limitary to innovate by the requirements or functions of products. For example, the surface of dinnerware should be smooth for the sake of using and cleaning. On the other hand, texture can be novel and creative in artwork and conceptual design. A distinct surface texture provides stimulation and even impression.

\subsection{Types of texture}

Scholars have categorized textures in visual art and designs from different perspectives. They are macroscopically sorted into 'tactile' and 'visual' in terms of sensation(Pipes, 2004) or summarized as 'actual', 'simulated', 'abstract' and 'invented'(Ocvirk et al., 2002) as shown in Fig. 2.

Tactile texture means the authentic and tangible surface of a substance, which "we can feel with our fingertips"(Pipes, 2004). It is the "real thing" and how the surface of a substance looks and feels (Ocvirk et al., 2002). It is also a tangible surface with a tactile impression. Real texture is a surface characteristic of materials or created by artists(Pipes, 2004) as shown in Fig. 3. Materials can be directly identified and perceived by touching and seeing the tex-

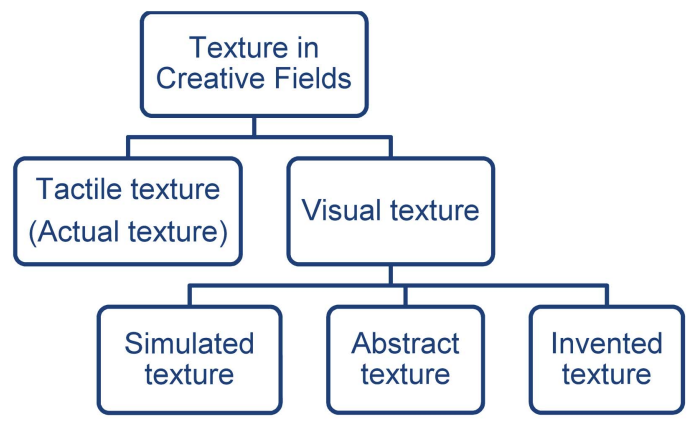

Fig. 2. Categorization of texture in visual art and designs. 


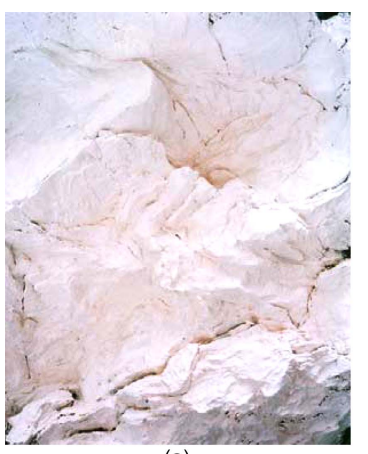

(a)

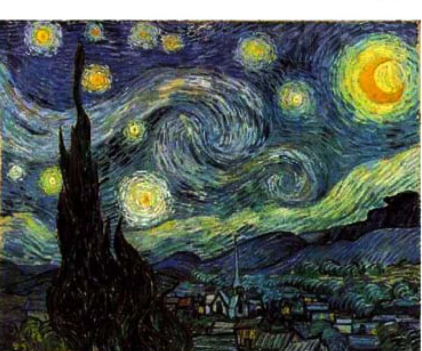

(c)

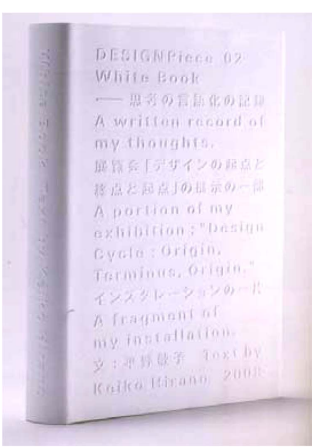

(b)

Fig. 3. Tactile texture. (a) Tactile texture of material, Chalk, B. Brunner, 2009. www.boltelang.com, (b) Texture of a book cover. Design Texture: Unique Materials and Finishes for Graphic Design, (c) Texture by brush strokes. Starry Night, V. van Gogh, 1889. www.vangoghgallery.com.

tures. The tactile texture of original material indicates the characteristic surface of a material itself. The created tactile texture is common and important in three-dimensional art and designs such as carving, sculpture, architecture, product surfaces and fashion. Tactile texture is also applied to the two-dimensional field, for instance impasto paintings and additional tactile qualities. The application of brush strokes is one of the main peculiarities in most of Vincent Van Gogh's oil paintings, which provides tactile texture with great impact on the viewer(Ellinwood, 2011).

Visual texture is the sensation perceived from the surface of materials or artificial creations, defined by Pipes(2004) as a thing "created by the hand of the artist", which specifies the implied twodimensional surface texture in art and design. There is no actual tactile sense that can be perceived from visual texture which is an important and developable element in two-dimensional fields. Visual texture shows a creative activity rendered by artists and designers with their imagination. The types of simulated texture, abstract texture and invented texture are divisions in visual texture creation.

Simulated texture, abstract texture and invented texture are divisions of visual texture creation(Fig. 4a). Simulated texture is a surface that looks like a real substance but is actually unreal(Ocvirk et al., 2002). The art style of trompel' oeil, which means "deceiving the eye" in French, is an extreme result of visual texture created by
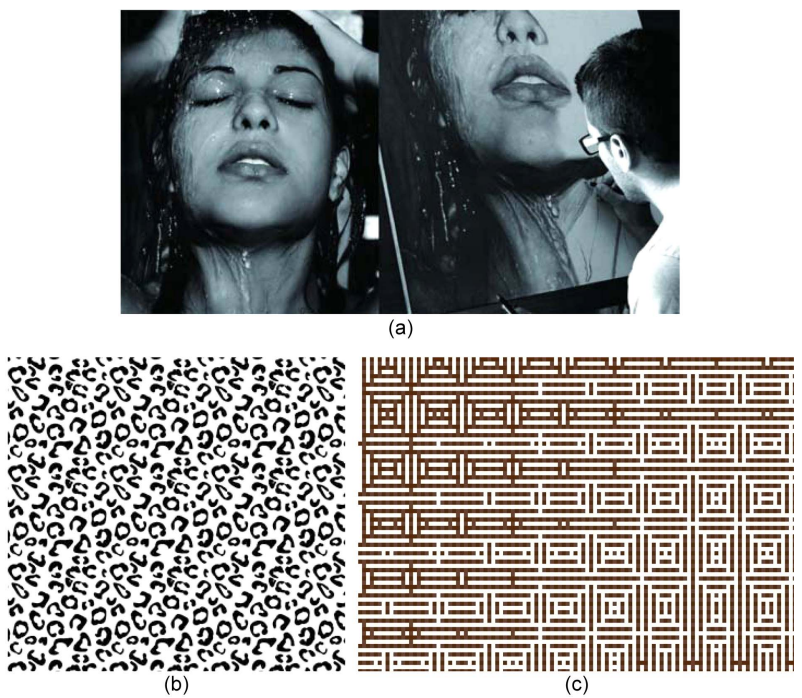

Fig. 4. Three types of visual texture. (a) Simulated texture in a photorealistic pencil drawing named Sensazioni by D. Fazio. diegokoi.it, (b) Abstract texture of leopard printing. www.nipic.com, (c) Invented texture. arts.unomaha.edu.

simulating real textures(Pipes, 2004). Simulated texture can trigger memories of a real object when people see simulated images(Gatto et al., 2000). Such a texture can suggest a certain feeling of a substance only without the sense of touch. Photography is a way to simulate textures, in which everything has its own textural look with light and cast shadows. However, artists and designers are not content to simply reproduce images of existing objects. Many novel visual textures are created to abstract real textures in the world, or invented to describe a creator's imagination. Abstracted texture, as the name implies, is created through abstract work(Fig. $4 b$ ), and is modified with a hint of the original texture to satisfy the intent of the creator. Abstraction mostly involves visual simplification(Texture, n.d.), and sometimes applies exaggeration. Abstract texture is the symbolization of an original object and has the function of decoration and can tell its observers what they see(Ocvirk et al., 2002). For decoration, invented texture is applied in the same way as abstract texture(Fig. 4c). Invented texture is different to abstract texture in the way that it has no simulated or hinted object in reality.

\subsection{Emphasis on Tactile Texture in Creative fields}

McCloud made a point that "the effect of sunlight on a textured surface is infinitely more interesting than on a smooth one, ... the shadows it creates on texture bring a surface to life"'(as cited in Hilliard \& Cliff, 2002). The three-dimensional surface is able to present various effects due to light and shadows on a surface. Aside from two-dimensional visual texture, three-dimensional tactile tex- 


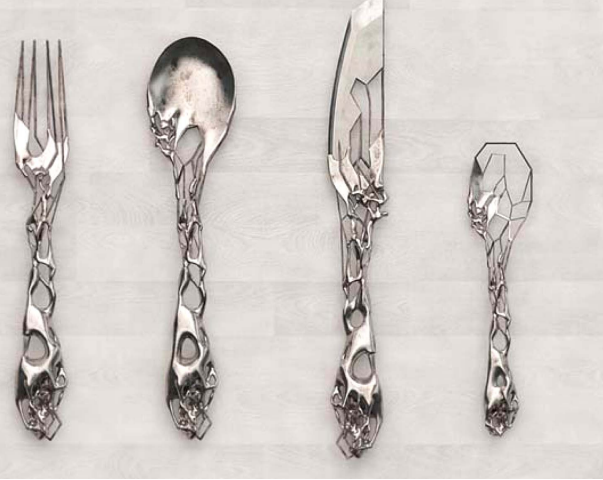

Fig. 5. Tableware texture designed by I. Bloch. creoflick.net

ture is the innovative point for surface design in fashion and textile. Furthermore, fashion designers usually borrow artists' concepts to help them create new designs(McDowell, 1984). The chasm between art and fashion has been fading away(Celant, 1997). It is not unusual to see that fashion designers work like an artist. To understand the status of texture in fashion and textile design, it is necessary to learn its feature in the integration of creative fields.

Texture is one of ingredients that can be manipulated to make art and design more innovative and interesting and "heighten an emotional impact" on the observers(Preble et al., 2002). Memories of texture will be recalled when the associated substance appears again. With the supplement from other elements, like color, value, shape and space, texture brings reality to design and suggests certain feelings and moods(Gatto et al., 2000). Many unprecedented textures appear on the surfaces of conceptual designs and artworks. In the tableware(Fig. 5) designed by Isaïe Bloch, texture becomes a primary factor beyond the mere function of food serving.

In architecture design, texture is one of the decorative elements. By coordinating light with color, texture plays an important role in "determining the materiality of the design and incorporating a sense of signage and public prominence"(Vetne, 2012). Surface textures show various traits of creativeness in architecture designs and can articulate, differentiate and vivify surfaces and objects so the aesthetic quality of architecture can be enhanced(Thomas, 2002). Antonio Gaudi's Cathedral of SagradaFamilia(Fig. 6a) is famous for its spectacularity created by cliff-like facades with intricate carvings and very few smooth surfaces(Pipes, 2003). Architects Jacques Herzog and Pierre de Meuron's works are characterized by the intriguing surface creation with various materials. Museum der Kulturen has been given a scaly textured crown over the top by the architects(Fig. 6b). Their work of Beijing National Stadium(aka the Bird's Nest) designed for the 2008 Olympics and Paralympics provides a strong visual effect through

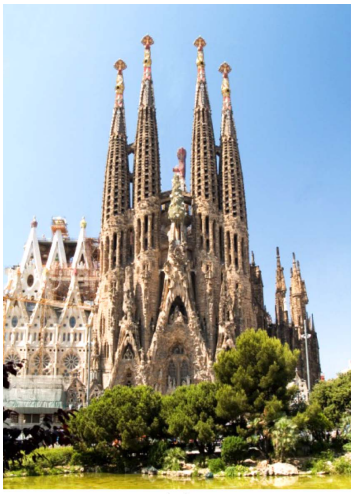

(a)

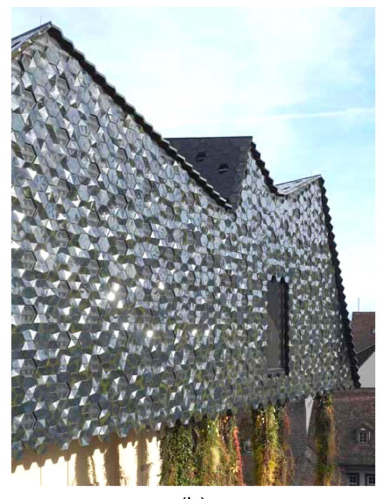

(b)

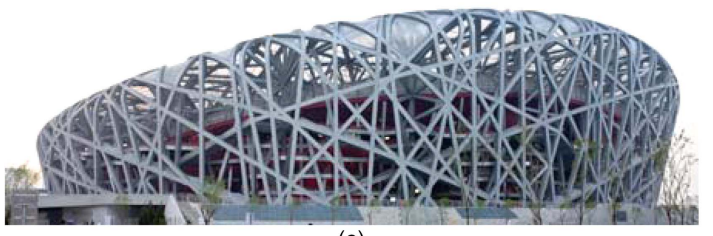

(c)

Fig. 6. Innovative textures in architecture design. (a) La Sagrada Familia, A. Gaudi and others, 1893-present, Barcelona. architecture.about.com, (b) Museum der Kulturen by Herzog and de Meuron. www.dezeen.com, (c) Bird's Nest by Herzog and de Meuron. www. dezeen.com.

the huge tactile surface on a creative shape(Fig. 6c).

Innovative texture is also notable in interior design. Designers can express their intangible design concepts by manipulating materials so as to provide visitors with a uniform style of environment and tangible feelings. Sergey Makhno and Vasiliy Butenko designed the interior of the restaurant "Twister" in Kiev, Ukraine(Fig. 7a). The decorative thatched sticks on the wall in the bar area simulate a bird's nest, and the seats resemble pods or cones with concave-convex to contrast with other smooth accessories. In the interior of the Richard Chai store in New York, fashion designer Richard Chai created a temporary retail installation in collaboration with Snarkitecture in October 2010(Fig. 7b). It was part of the Building Fashion series of Chai. Visitors which invoked a vision of a glacial cavern by erosive and extensive white textures manually cut as
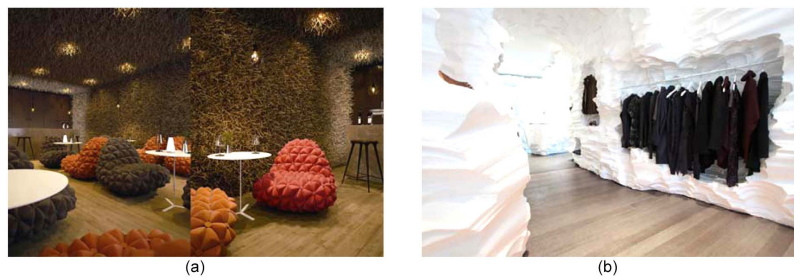

Fig. 7. Interior innovative textures. (a) Restaurant "Twister" by $\mathrm{S}$. Makhno and V. Butenko. www.archdaily.com, (b) Richard Chai store in New York. www.snarkitecture.com. 


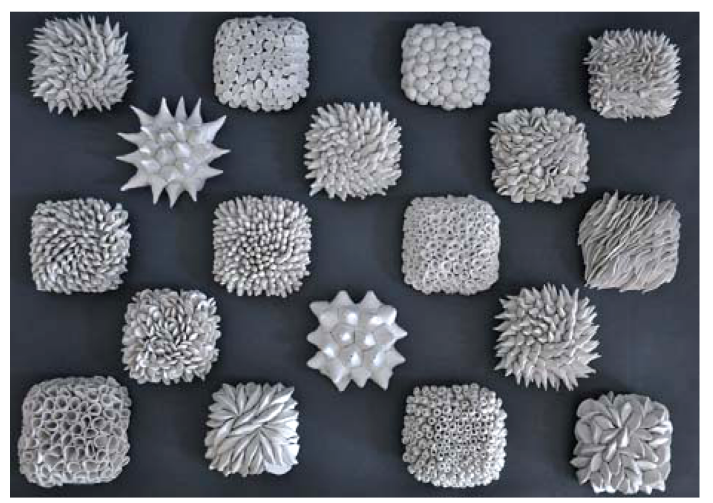

Fig. 8. Texture creation in ceramics by Heather Knight. www.heatherknight ceramics.com.

sculpted walls.

For ceramics artist Heather Knight, texture is the essence of her work(Fig. 8). She hopes to bridge modern design and the natural world by paring down the essence of things to repetitive texture and basic form with her work, and she loves the way a texture can produce the illusion of movement, the way light and shadow play with one another(“About the artist”, 2011). As developed technology and advanced materials have been applied to many design fields to attain concepts, application of innovative tactile texture as a major element is common for practical design nowadays.

As shown by the above three-dimensional tactile textures, texture plays an important role in determining the effects of outcomes in creative fields. Texture is a way for artists and designers to create surface interests for expressing concepts and emotions, and also serves as reference to ideas and skills for fashion design.

\section{Surface Texture in Fashion and Textile Design}

\subsection{The feature of texture in fashion and textile}

Fashion is a visual product, especially its first impression (Ellinwood, 2011). It is the final form, organized and arranged from parts, including design concepts, aesthetic experience, trendy elements and materials. Fashion design is informative with highly visual content integrated with the basic elements of line, form, space, texture, and color(Horn \& Gurel, 1981). Texture as one of the basic elements refers to the surface look and the feel of material that can be divided into two characteristic groups: visible appearance and performance(Brannon, 2011). Performance characteristics indicate the properties and functions of a material and "must be tested by manipulating the fabric"(Brannon, 2011). For example, when designing children's clothes and accessories the texture must be soft and comfortable, even to a baby's sensitive skin. In this

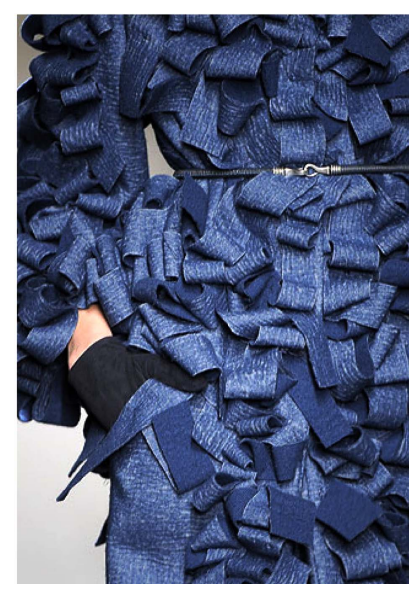

Fig. 9. A textural dress with folded cloth of Bottega Veneta 2008/2009 F/W. shows.vogue.com.cn.

case, texture concerns the designer's decision on right materials for a product. However, fashion design creates visual appearance and designers' innovative texture creations focus on the appearance of surface texture to enhance the visual and aesthetic aspects of garment design.

Texture roughness of fashion design depends on material quality and how the material is manipulated or grouped. As shown in the Bottega Veneta denim dress, textural effects are observed on both the fabric and the whole dress(Fig. 9). However, the fabric loops on the dress look much rougher than the fabric. The different sizes of texture components determine the effect of roughness. Texture also concerns the weight or visual weight of fashion and textile. The weight of material is related to the design as well as the final outcome(Udale, 2008). For textile texture, the weight of yarn and the size of stitches or weave affect the appearance. For other methods of texture creation based on fabric or new inventions, the consideration of the size and weight of the applied material is necessary, which is able to affect the appearance of silhouette by the roughness or smoothness of a material, and also the color by either reflecting or absorbing light from the surface(Stone, 2004).

The creation of surface texture is an open-ended process of innovation which can be realized by multifarious techniques and methods. In comparison with color, texture is less affected by fashion trends and has more room for creativeness. In general, texture and color form the surface appearance. In comparison with line, form and space, texture is more flexible in terms of physical factors, wearability and function as it mainly deals with surface interests.

Evolution of surface texture application and creation in fashion Texture is generally considered as the surface and quality of fabric. Hua(2003) argued that texture performance in fashion design depends on fabric texture. As the most basic and conventional 


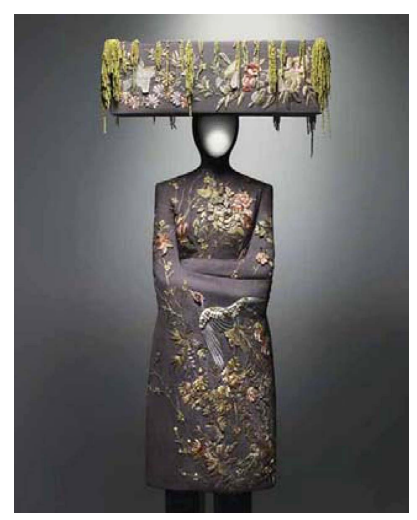

Fig. 10. Embroidered texture of ensemble, Alexander McQeen, 2001 S/S. blog.metmuseum. org.

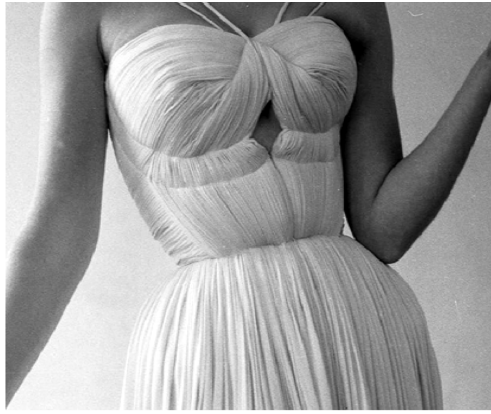

ig. 11. Texture of draped fabric, Madame Grès, 1955. www.tumblr.com.

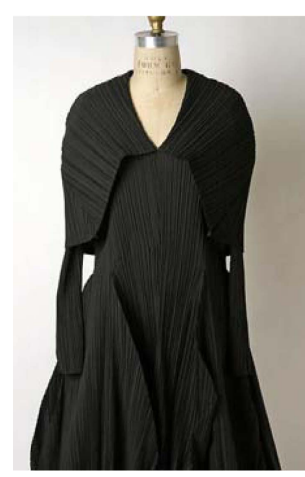

Fig. 12. Texture of pleats, Issey Miyake, 1985. pinterest.com. material for fashion designers, fabric has attached to fixed implications for expressing different aesthetics and emotion. For instance, chiffon provides a feminine and sophisticated feel by its light and smooth quality; denim shows sportiness because it is firm and semi-smooth(Davis, 1996); and nubble linen looks unadorned (Hua, 2003). Fabric provides various types of feel and meanings for fashion design by its diverse textures.

Even so, a fashion designer is not restricted to ready-made fabrics for their creation. Chemical, mechanical or handmade treatment, embroidery and embellishment are effective methods conventionally used by designers to create fabric texture. Embroidery and embellishment are traditional skills for decorating the surface and fabric in both traditional and modern fashion. Fig. 10 shows Alexander McQueen's design, an outfit decorated by embroidery with silk thread and amaranthus on the pink and gray wool jacket, and a hat(Bolton et al., 2011). The embroidery is three-dimensional and tactile and performs an arresting textural look for the surface of simple shapes. Fabric can be transformed into various styles by undergoing different treatments. Germaine Émilie Krebs, also known as Madame Grès, was a famous couturier in the early 20 th century. She was skilled in creating delicate pleats with draping fabric as the surface appearance of dresses(Fig. 11). The pleats enhance the effect of an ordinary fabric surface so as to be a unique decorative element in the simple dress shape, which "symbolizes the very essence of couture and rigor of minimalism"(Foiret, 2011). Pleated fabric launched by Issey Miyake is an iconic texture in fashion design made from a single piece of polyester fabric by a pleat machine(Fig. 12). The texture of pleats on a garment embodies a creative surface characteristic for fashion and textile in the 1980s and 1990s. Fig. 13 shows an asymmetrical dress by Yoshiki Hishinuma known for his textile innovations. The textural fabric has been intentionally shrunk and creased by undergoing a heat treatment and bonding polyurethane. In Christian
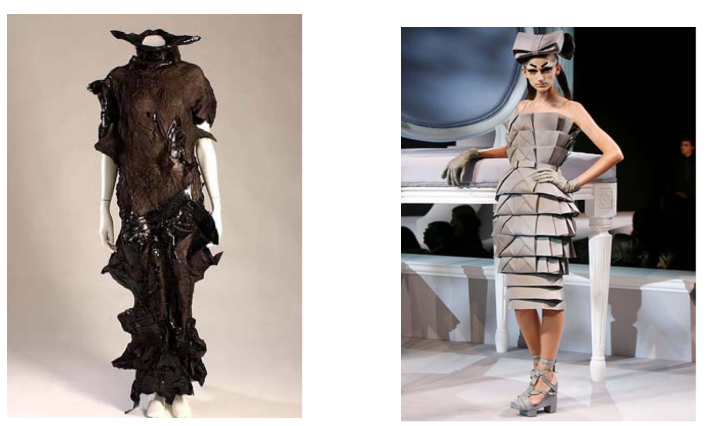

Fig. 13. Texture on black dress, Fig. 14. Origami texture in YoshikiHishinuma, 1999/2000 F/ Christian Dior 2007 S/S couture $\mathrm{W}$, fitnyc.edu.

collection, www.vogue.com.

Dior's 2007 Spring/Summer couture collection inspired by Madame Butterfly, texture created by origami was employed as one of the main elements to express orientalism(Fig. 14).

In addition to textile, fashion designers also apply various trimmings and even non-clothing materials for surface creations. In Fig. 15 , the trimmings of golden metal are used for decoration with

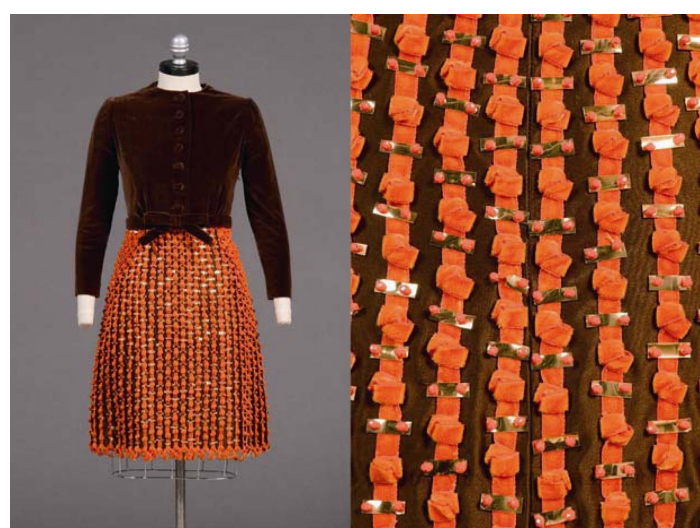

Fig. 15. Texture decoration with metal plates and velvet ribbons, Arnold Scassi, 1965-67. blog.fidmmuseum.org. 


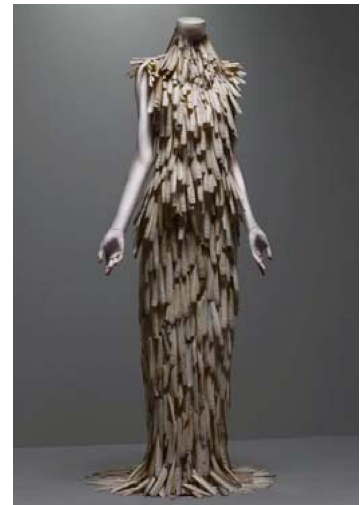

Fig. 16. Surface texture formed with shells, Alexander McQeen, $2001 \mathrm{~S} /$ S. blog.metmuseum.org.
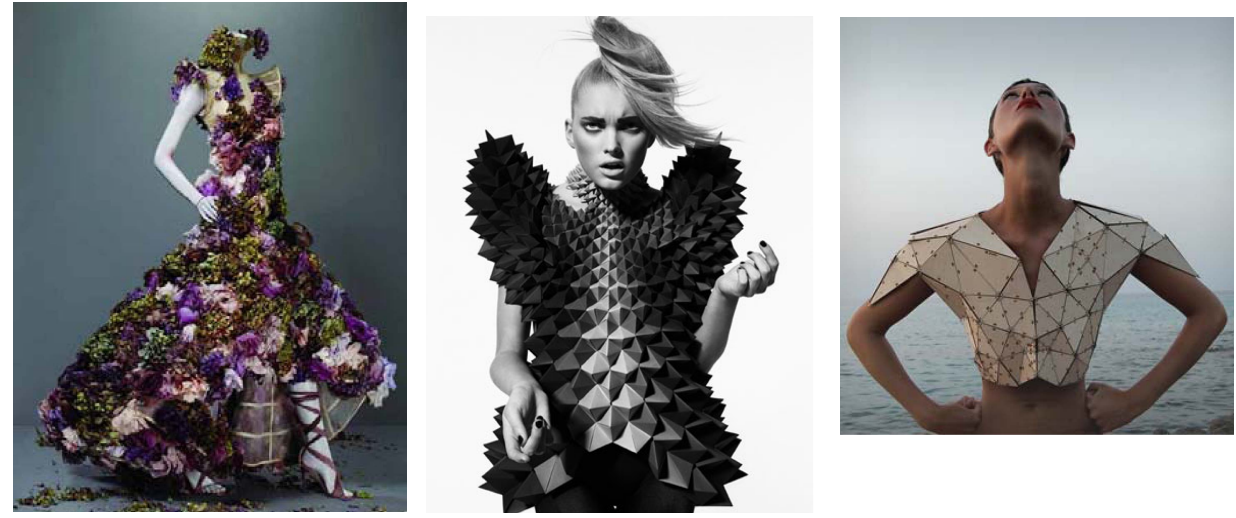

Fig. 17. Surface texture creation with Fig. 18. Surface texture of paper Fig. 19. Structural wooden surface fresh flowers, Alexander McQeen, construction from Sandra Backlund's texture of Wooden T-shirt by Pauline 2007 S/S. blog.metmuseum.org. Ink Blot Collection 2007. www.sand Marcombe, 2012. www.journal-du-
rabacklund.com.

strips of velvet on the dress surface. For Alexander McQueen, materials like shells, feathers, hairpieces and fresh flowers are used to form the entire dress surface and produce a strong visual impact. Fig. 16 shows a dress surface formed by stripped and varnished shells(Bolton et al., 2011). Fig. 17 shows a dress from the collection of Sarabande Spring/Summer 2007. The base of the dress made of nude silk organza is fully embroidered with fresh flowers and silk flowers(Bolton et. al, 2011). As shown in Fig. 18 and Fig. 19, designers Sandra Backlund and Pauline Marcombe used paper or wood to construct structural texture for garment surfaces with unusual outlines. The surface interests are enhanced by various trimmings in fashion design. Through application of uncommon materials such as hairpieces, paper and wood, more ingenious visual effects are created.

With the development of technologies such as three-dimensional printing, laser, and smart technology, surface texture has more openings for creating novelty in fashion design. Hussein Chalayan is renowned for his innovative use of materials and new technologies. Fig. 20 shows his transformable dress from the One Hundred

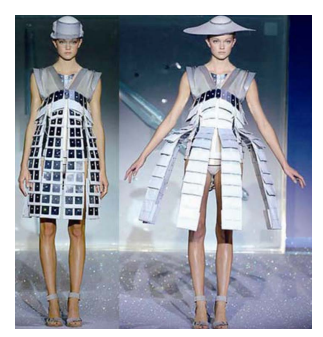

Fig. 20. Texture in smart electronic fashion, Hussein Chalayan, $2007 \mathrm{~S} / \mathrm{S}$. $w w w$. style.com.

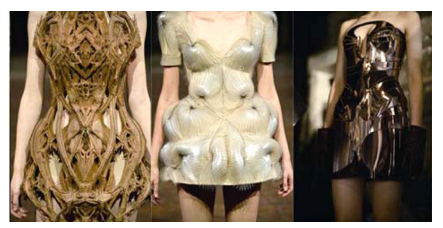

Fig. 21. Surface texture created by $3 D$ printing, laser, and electroplating bath techniques Iris van Herpen, $2012 \mathrm{~S} / \mathrm{S}$. www.irisvanherpen.com. and Eleven Spring/Summer 2007 collection. The surface texture and shape can transform as the dress is controlled by smart electronic technology. Iris van Herpen is another fashion designer notable for application of innovative techniques. She applied not only 3D printing and laser, but also electroplate bath techniques in her Micro Haute Couture Spring/Summer 2012("Micro by Iris van Herpen", 2012). Surface textures in the collection were bizarre and unprecedented, which were inspired by scaly organisms such as vermins, lice and termites(Fig. 21). The N12 bikini created by designers Jenna Fizel and Mary Haung of Continuum Fashion is known as the first 3D-printed bikini, which was developed in collaboration with 3D printing company Shapeways("N12", 2011). The surface texture of N12 is designed in an elegant style, which is not only created for aesthetic purposes, but also for an arrangement for the structure of 3D-printed material(Fig. 22). For fashion designer Alba Prat, the high-tech world is the inspiration for her designs. She created a tactile surface texture in cube patterns to express his digitalized concepts as shown in Fig. 23.

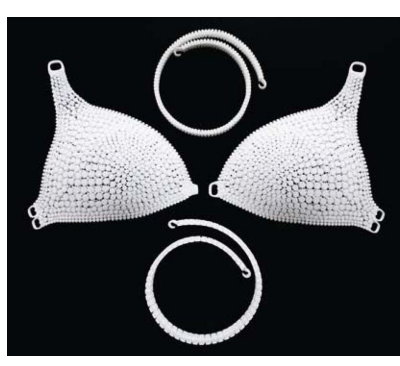

Fig. 22. 3D-printed bikini, N12, Jenna Fizel \& Mary Haung, 2011. www.continuumfashion.com.

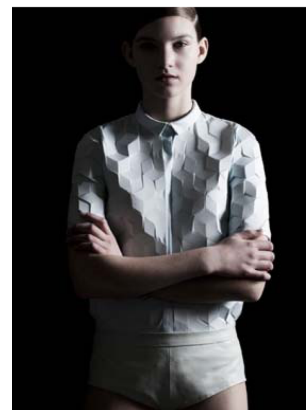

Fig. 23. Surface texture in cube. patterns, Digitalized, Alba Prat, 2012. www.pleatfarm.com. 
Surface texture evolves with the technology development and the public need of novelty. By observing various innovative applications and creations, this study cannot be confined to knowledge of fabric texture because many innovative materials and techniques have been used for texture creation besides traditional fabric application or manipulation. According to previous studies, the evolvement of surface texture is found in three aspects. Firstly, the meaning of texture in fashion design broadens as the surface performance of garments and the textures of multiple applied materials are the elements of texture creation. Secondly, the appearance of surface texture tends to be a novel feature without restricting to decorative purposes and becomes first and foremost in visual effects. Furthermore, methods of creating surface texture have great development by using innovative techniques and technology.

\subsection{Classification of surface texture in fashion and textile designs}

Flesishman and Quaintance stated that classification is important in theoretical development, and is not only a description of an object, but a group work by comparing similarities and dissimilarities with an explicit method(as cited in Paluszak, 2008). Generally, classification is the grouping of homogeneous data from the large amount of heterogeneous data(Gupta \& Gupta, 2011; Mukherjee, 1983). The purpose of classification is to sort things based on likeness and unlikeness through grouping or sub-grouping and to arrange the contents into the most convenient order(Sharma \& Sharma, 2007). It can be used to identify inclusion or exclusion within a particular group, and serve as a guideline for users to develop strategies of predetermination.

Texture is studied within the range of fabric products focusing on quality and characteristics of the surface and performance of fabric. It is classified into warm and cool types according to thermal characteristics of fabric(Brannon, 2011) and sorted on the basis of fabric properties or styles(Hua, 2003). This study focuses on ingenious surface appearances in fashion and textile design. A number of cases of garments with effective surface textures are studied for tracing the evolution and the latest feature of surface texture. In terms of visual aesthetics, a new classification of surface texture is established through seeking the actuality and evolution of surface texture.

Classification can be done according to attributes(Kothari, 2009). This study proposes surface texture classification on the basis of texture attributes of forming a mechanism with aesthetic consideration. A large number of surface designs with various techniques are first classified as three-dimensional tactile texture and two-dimensional visual texture from a macroscopic view. Visual texture in fashion and textile fields signifies pattern design in a two-

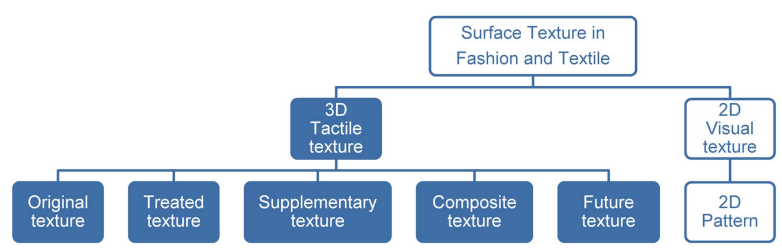

Fig. 24. Classification of surface texture in fashion and textile design.

dimensional motif produced by jacquard weaving or two-dimensional surface treatments such as printing and laser engraving. This study concerns three-dimensional tactile texture because this type has more techniques and methods for creation of ingenious surface texture. From both aesthetic and technical perspectives, similar characteristics of forming mechanisms are categorized into original texture, treated texture, supplementary texture, composite texture and future texture(Fig. 24). Each group is equally important and independent to each other.

\subsubsection{Original Texture}

Original texture is the original surface texture of ready-made fabric. Its appearance and properties do not change before or after application. Various surface textures of different types of wovens, knits, leather and fur belong to the class of original texture. The surface appearance of original-texture garments depends on yarn weight, stitch size, and yarn structure. Surface interests of garments are defined by surface quality of fabric. In this case, choosing the right surface texture of material is the important factor for fashion designer to render the surface of garment design. Fig. 25 shows a Comme des Garçons dress shaped by fabric pieces with different original textures such as wovens and lace.

\subsubsection{Treated texture}

Treated texture is created by fabric treatment, and is closely related to original texture which is the underpinning of treated tex-

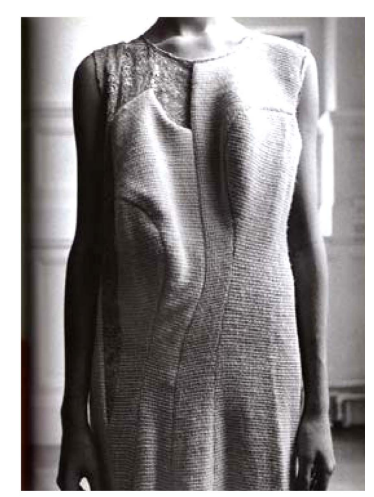

Fig. 25. Original texture of fabrics, dress by Comme des Garçons, photo by Steven Meisel. Vogue Italia, July 1997. www.vogue.it. 


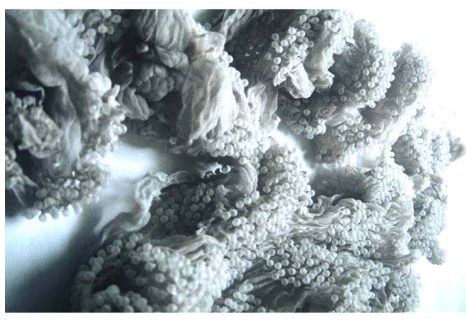

(a)

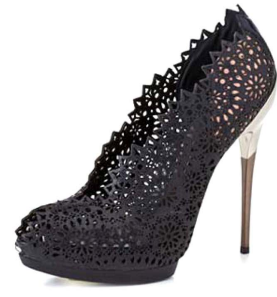

(b)
Fig. 26. Treated texture (a) Treated texture by shibori. Pearlbubbles, Yuh Okano, shibori.org, (b) Treated texture of a laser cut shoe, Salvatore Ferragamo, 2009/2010 F/W. www.ferragamo.com.

ture. Fabric treatment can be chemical, mechanical or handmade, and change or enhance the original surface appearance. There is a wide variety of traditional treatments for enhancing fabric appearance, such as pleating, fold, shibori, metalizing, singeing and etc. With new technology in fashion and textile, innovative methods have been applied to creation of surface texture. Treatments provide various surface textures for fashion design without being restricted to surface texture of ready-made fabric. Examples of treated texture are shown in Fig. 26.

\subsubsection{Supplementary texture}

Supplementary texture indicates additional materials attached to fabric surface for decorative purposes. The attachment changes the surface appearance. The quality and characteristics of additional materials and their appearance on the fabric determine the effects of the created surface texture. Embroidery and embellishment give a decorative and three-dimensional look and add to surface interests(Udale, 2008). They are the most typical methods for making supplementary texture such as decoration on fabric surface with removable additions of stitches, trimmings or decorative fabrics, as shown in Fig. 27.

\subsubsection{Composite texture}

Composite texture is characterized by a mixed effect through
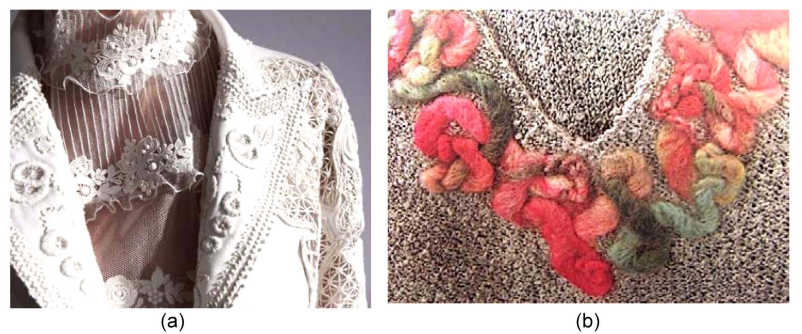

(b)

Fig. 27. Supplementary texture. (a) Supplementary texture by embroidery, Valentino Haute Couture, 2012 S/S, treshaute.tumblrcom, (b) Supplementary texture by needle embellishment. Needle felting by hand or machine: 20 projects using easy-to-learn techniques (2007), p.61.

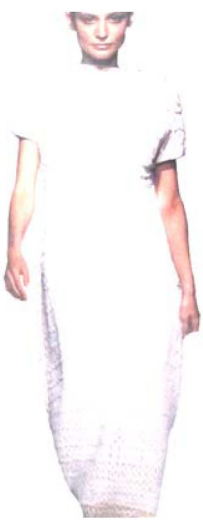

(a)

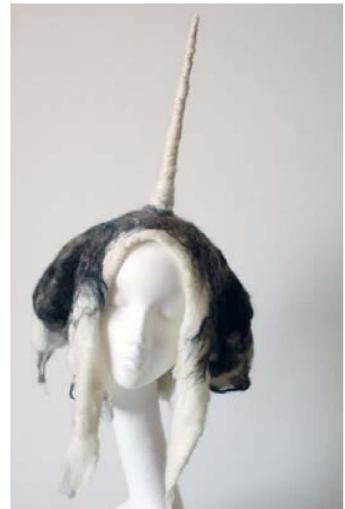

(b)
Fig. 28. Composite texture (a) Composite textureby bonding, Maya Bramwell, 1999. Knitwear in fashion (2002), p. 87, (b) Composite texture by needle felting, Needle felted hat, Kreuzzz, 2012. www.jue.so.

synthesizing two or more materials. The texture is produced by mixing fibers and fibers, fibers and fabrics or fabrics and fabrics. In some cases, the original materials are hard to identify. Bonding and lamination are typical techniques for composites. Surface textures of most composite materials are determined by the surface quality of the shell fabrics. But by ingeniously combining different materials, the surface interest can also be created as a composite texture with both the shell fabric and the base fabric. As shown in Fig. 28a, the stitch pattern of knitted base fabric creates the composite texture in company with the non-woven shell fabric. Moreover, felting, wet or dry, is an effective technique for making composite textures by means of mixing fibers. Both supplementary texture and composite texture can be created by dry felting with barbed needles. While composite texture is a texture of assembly, the materials of supplementary texture are additional and removable. Fig. 28b shows a needle-felted hat with composite texture made from wool, bamboo and silk.

\subsubsection{Future texture}

Future texture denotes unconventional or newly-invented textures produced with innovative materials by innovative techniques. Modern garment technology makes possible production of a wide variety of materials, models, structures and patterns(Matkoviæ \& Marija, 2010). By using innovative technologies such as smart fashion technology(Fig. 20), 3D printing(Fig. 22), or unconventional materials such as paper(Fig. 18), wood(Fig. 19) and metal, the creation of future texture breaks through the traditional appearance and process of fashion design or focuses on the futuristic concept beyond the functional aspect of fashion. The innovative techniques provide more opportunities and methods for executing unrealized design concepts and thus creating more creative surface 
Table 1. Classification of surface texture in fashion and textile design

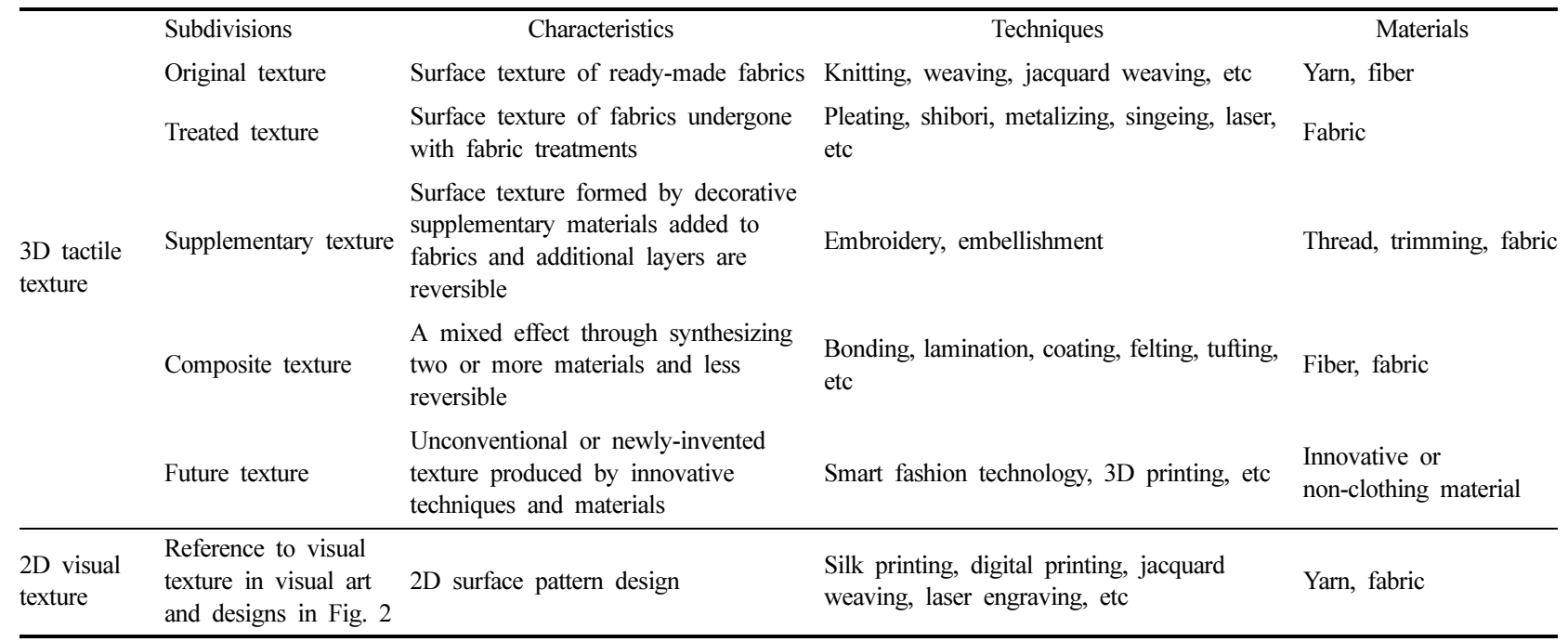

textures.

\section{Conclusion}

As clothing has evolved well beyond its original functional purposes of warmth and social decency, these days frequently lending itself to personal displays of expressionism or of a designer's concept, the design concept is itself emphasized at the center of the creation process. The unique element of surface texture plays an important role in expressing a designer's idea and sense of the effect of aesthetics on fashion design. In some conceptual fashion design, surface texture appears as the leading element in the creation. The creation and application of surface texture in fashion and textile design evolved along with the thriving design concepts and development of fashion technology. The ingenuity of surface textures is closely related to the designer's concept and creative skills. More innovative ideas for fashion design have been presented with novel surface interests. In conclusion, texture, especially for aesthetic reasons, is no longer merely the appearance and the quality of the fabric, but is the look of the entire surface arrangement in fashion design.

In this study, surface texture is considered from breaking through the conventional theory and concept of texture which restrict to the performance and surface quality of fabric. According to the latest features of surface texture explored from tracing its evolution, texture in fashion and textile design has been newly-defined as the surface performance of garments by means of manipulating materials. Textures of applied materials and the result of manipulation are elements of texture creation. The new classification of surface texture focuses on the latest feature of fashion and textile design, and is established based on the texture attributes of technical mechanism and visual aesthetics. The five groups of surface texture are equally important to each other in terms of traditional sense and new understanding of surface texture. Original texture denotes the texture of fabric corresponding with the traditional sense of texture in fashion and textile. Additionally, treated texture, supplementary texture and composite texture indicate different surface textures by manipulating fabrics and other materials. Furthermore, future texture generates textures created by innovative technology and materials.

The achievement of the study can be significant to both the theoretical research and the practical works of fashion and textile design. Firstly, the study fills gaps of theoretical study in term of texture. Secondly, the new framework and technical suggestions can be employed in the development of surface textures with various applicative techniques. Thirdly, new terms generated from this study can facilitate the communication of surface texture creations in both conceptual and industrial fields of fashion design.

\section{References}

'About the artist'. (2011). Element Clay Studio. Retrieved June 34, 2012, from http://www.heatherknightceramics.com/content.html?page $=6$

Beaney, J. (1978). Textures and surface patterns. London: Pelham. Black, S. (2002). Knitwear in fashion. London: Thames \& Hudson. Bolton, A., Sundsbo, S., Blanks, T., \& Frankel, S. (2011). Alexander McQueen: savage beauty (1st ed.). New York: Metropolitan Museum of Art.

Brannon, E. (2011). Designer's guide to fashion apparel. New York: Fairchild.

Buckner, R. (1995). Art and design, Book one. Sydney: McGraw-Hill. Celant, G. (1997). To cut is to think. In G. Celant (Ed.), Art/ fashion . New York: Power House Books.

Davis, M. (1996). Visual design in dress (3rd ed.). Upper Saddle River: Prentice Hall. 
Ellinwood, J. G. (2011). Fashion by Design. New York: Fairchild Books.

Fan, J., Hui, C. L. P., \& Lu, D. (1999). Towards the objective evaluation of garment appearance. International Journal of Clothing Science and Technology, 11(2/3), 151-159.

Foiret, C. (2011, April 10). Madame Grès exhibition at bourdelle. Trendland. Retrieved December 10, 2012, from http://trendland.com/ madame-gres-exhibition-at-bourdelle/

Gatto, J., Porter, A., \& Selleck, J. (2000). Exploring visual design: the elements and principles (3rd ed.). Worcester: Davis Publications.

Griepentrog, L., \& Richards, P. (2007). Needle felting by hand or machine: 20 projects using easy-to-learn techniques. Wisconsin: Krause publications.

Gupta, M., \& Gupta, D. (2011). Research methodology. New Delhi: Prentice-Hall of India.

Horn, L., \& Gurel, M. (1981). The second skin. Boston: Houghton Mifflin.

Hilliard, E., \& Cliff, S. (2002). Fabric: the fired earth book of natural texture. London: Pavilion Books.

Hua, M. (2003). Fashion aesthetics. Beijing: China Textile \& Apparel Press.

Kothari, C. (2009). Research methodology: Methods and techniques. New Delhi: New Age International Pvt Ltd Publishers.

Matkoviæ, P., \& Marija, V. (2010). The power of fashion: The influence of knitting design on the development of knitting technology. Oxford: Berg Publishers.

McDowell, C. (1984). McDowell's directory of twentieth century fashion. London: Frederick Muller.

'Micro by Iris van Herpen'. (2012, February 15). Pleatfarmer. Retrieved November 20, 2012, from http://www.pleatfarm.com/ 2012/02/15/micro-by-iris-van-herpen/

Mukherjee, R. (1983). Classification in Social Research. Albany: State University of New York Press.

'N 12'. (2011). Continuum Fashion. Retrieved December 12, 2012, from http://www.continuumfashion.com/N12.html
Ocvirk, O., Stinson, R., Wigg, P., Bone, R., \& Cayton, D. (2002). Art fundamentals theory \& practice (9th ed.). New York: McGraw-Hill.

Paluszak, D. (2008). A Human Error Classification System for Small Air Cargo Operators.Master's thesis, State University of New York at Buffalo, Buffalo. Retrieved December 29, 2012, from http:// books.google.com.hk/books?id=EvrjIbW7HlEC\&printsec $=$ frontcover $\& \mathrm{dq}=$ inauthor:\%22Douglas $+\mathrm{J} .+$ Paluszak $\% 22 \& \mathrm{hl}=\mathrm{zh}-$ $\mathrm{CN} \& \mathrm{sa}=\mathrm{X} \& \mathrm{ei}=0 \mathrm{UoCUYumHITtiAfRhIAo \& ved}=0 \mathrm{CDEQ6AEwA}$ $\mathrm{A} \# \mathrm{v}=$ onepage\&q\&f$=$ false

Pipes, A. (2003). Foundations of art and design. London: Laurence King.

Pipes, A. (2004). Introduction to design. Upper Saddle River: Prentice Hall.

Preble, D., Preble, S., \& Frank, P. (2002). Art forms: an introduction to the visual arts (7th ed.). Upper Saddle River: Prentice Hall.

Sirikasemlert, A., \& Tao, X. (2000). Objective evaluation of textural changes in knitted fabrics by laser triangulation. Textile Research Journal, 70(12), 1076-1087.

Sharma, C., \& Sharma, A. (2007). Library Classification. New Delhi: Atlantic Publishers \& Distributors.

Stone, E. (2004). The dynamics of fashion (2nd ed.). New York: Fairchild Publications.

Takahashi, K. (2010). Design Texture: Unique Materials and Finishes for Graphic Design. Tokyo: PIE International.

Texture. (n.d.). University of Nebraska. Texture. Retrieved November 22, 2012, from http://arts.unomaha.edu/art/ART1100/texture.htm

Thomas, D. (2002). Architecture and the urban environment: A vision for the new age (1st ed.). Woburn: Architecture Press.

Udale, J. (2008). Basics Fashion Design 02: Textiles and Fashion. Lausanne: AVA Publishing.

Vetne, E. (2012). Art and architecture: New life for haverhill'swingate street arts district. Cambridge: ProQuest.

(Received 31 December 2012; 1st Revised 16 February 2013; 2nd Revised 22 May 2013; Accepted 10 June 2013)

Copyright (C) The Society of Fashion and Textile Industry. 2013. This is an open access article distributed under the terms and conditions of the Creative Commons Attribution Non-Commercial license (http://creativecommons.org/licenses/by-nc/3.0/), which permits unrestricted non-commercial use, distribution, and reproduction in any medium, provided the original work is properly cited. 